\title{
A beleza, joder, a beleza
}

\section{Rui Pina Coelho}

Título: A casa da força (2009). Autora: Angélica Liddell. Encenação: Angélica Liddell. Figurinos: Josep Font e Angélica Liddell. Desenho de luz: Carlos Marquerie. Assistente de desenho de luz: Félix Gama. Som:Félix Magalhães. Interpretação: Maria Morales, Lola Jimenez, Getsemani de San Marcos, Angélica Liddell, Perla Bonita, Cynthia Aguirre e Maria Sánchez. Violoncelo: Pau de Nut. Mariachis: Orquesta Solis. Campeão de Strongman de Espanha: Juan Carlos Heredia. Enfermeira: Ana Teresa Poço. Produção: Atra Bilis e Laboral Teatro. Local e data de estreia em Lisboa: Culturgest, Grande Auditório, 11 de Fevereiro de 2011.

A dor fisica não tem voz, mas quando, por fim, encontra uma voz, começa a contar uma história.

Elaine Scarry (1985: 3, trad. minha')

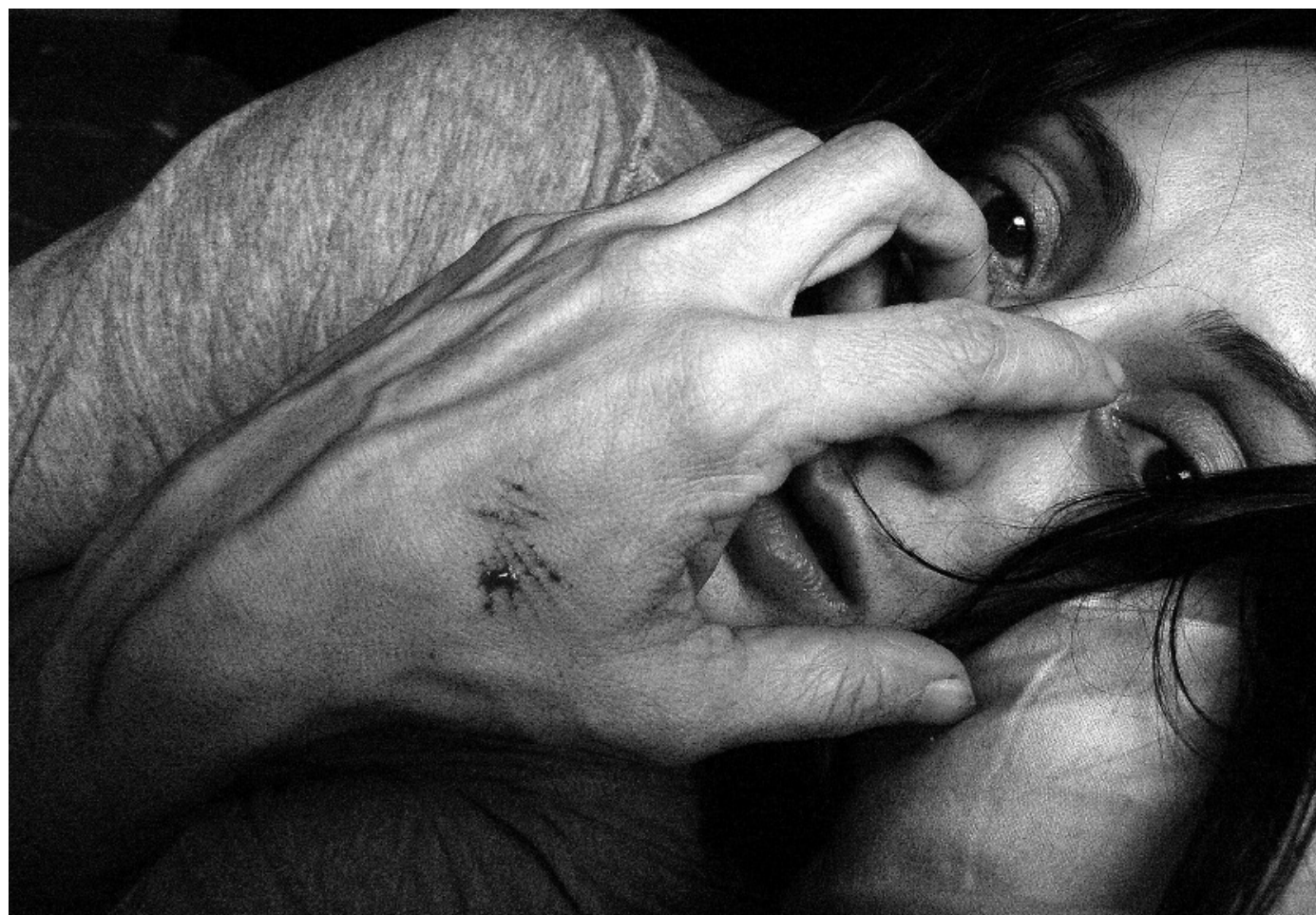

"Tenho a convicção de que a ferramenta mais poderosa na performance contemporânea é o próprio artista", declara Marina Abramovic (apud Conroy 2010: viii). E este é precisamente o campo de trabalho de Angélica Liddell, pseudónimo da catalã Angélica González (1966). Para além de ser uma das mais vibrantes dramaturgas contemporâneas vindas de Espanha, é também produtora, encenadora, actriz, poetisa e artista plástica. A sua actividade cénica, plural e diversa, combinando escrita e encenação, inscrever-se-á naquilo que a Bruno Tackels tem vindo a descrever como escritas de palco ${ }^{2}$. A este respeito, e muito claramente, Liddell declara em entrevista a Christilla Vasserot, reproduzida no programa para a apresentação na Culturgest: "Utilizo o palco como um meio. [...] Os meus textos são concebidos para serem montados, são escritos durante um processo de encenação". Fundadora da companhia Atra Bílis Teatro, de Madrid, em 1993, com Gumersindo Puche, tem sido presença regular (e discreta) no festival Citemor (onde apresentou Lesiones incompatibles con la vida, Broken Blossoms, Yo no soy bonita e a vídeo-instalação Temor y temblor, em 2007; Boxeo para células y planetas, 2008; e, em 2009, Te haré invencible con mi derrota ${ }^{3}$. Tendo recebido diversos prémios internacionais, Liddell alcança um reconhecimento mais alargado após presença no Festival de Avignon em 2010, com os espectáculos $A$ casa da força, precisamente, e 0 ano de Ricardo (este ano regressa com Maldito sea el hombre que confia en el hombre: Un projet d'alphabétisation). 


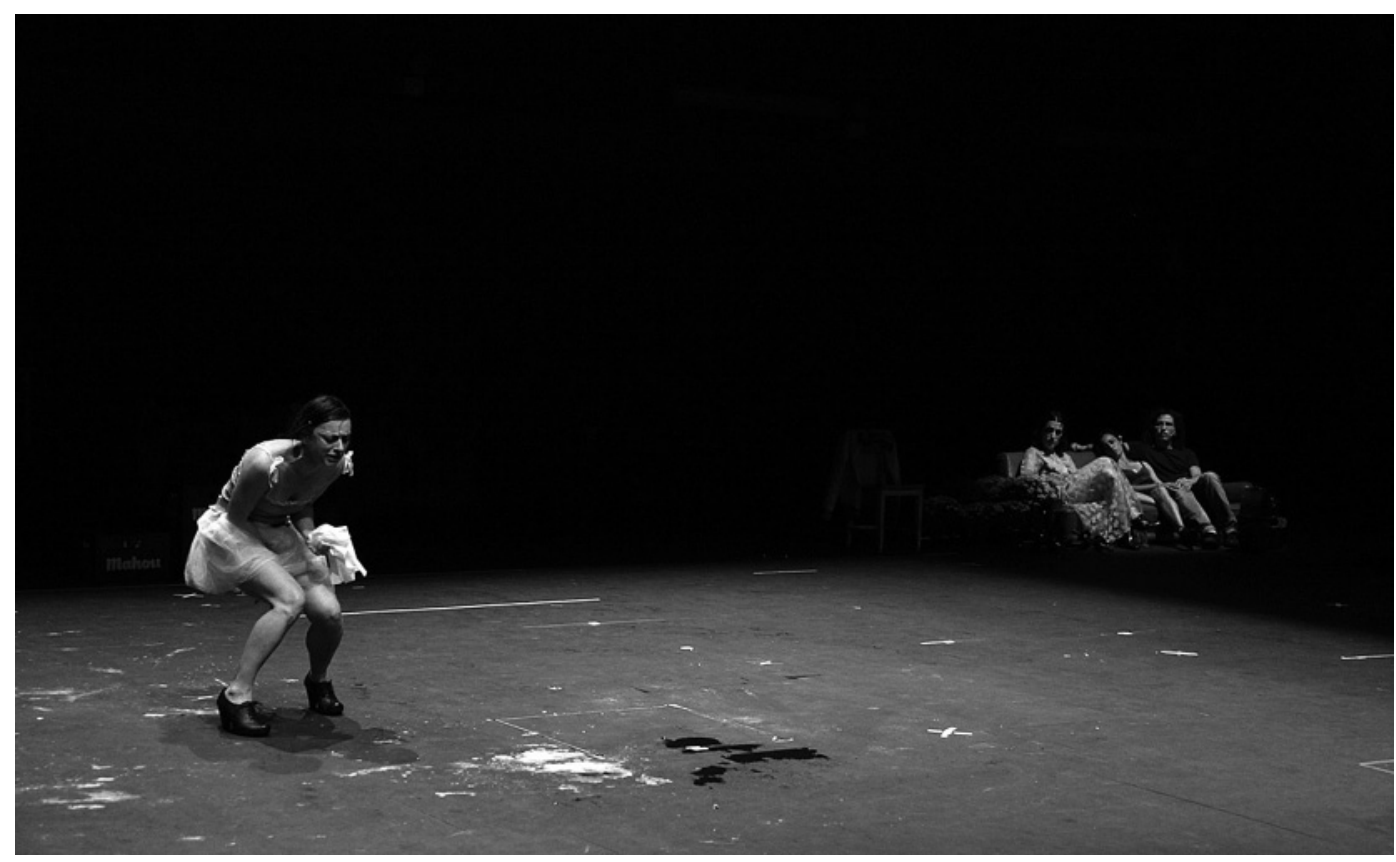

$\mathrm{v}$

A casa da força de Angélica Liddell, Atra Bílis, 2011 fot. Julio Calvo.

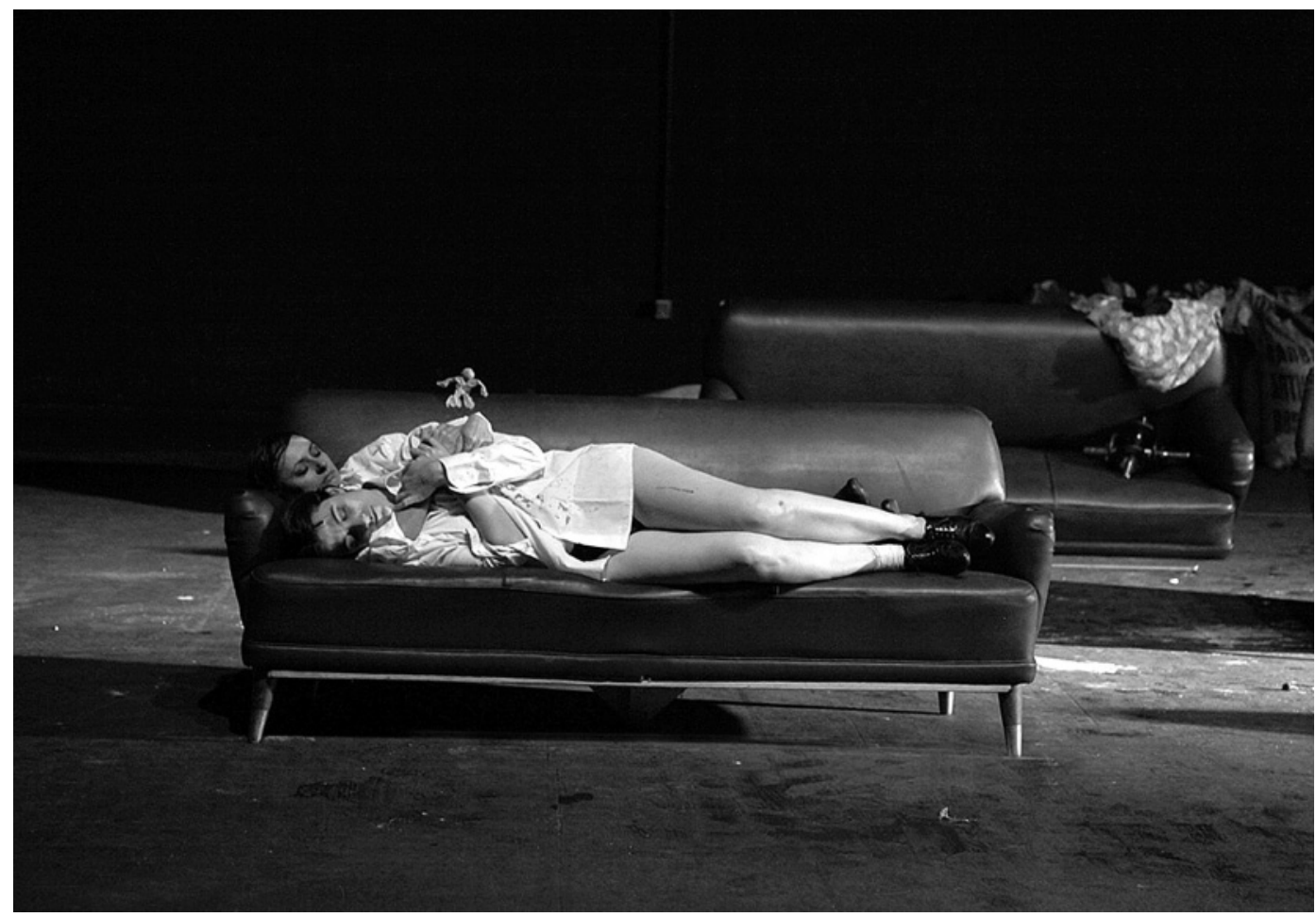

Teatro de febre intensa, Liddell trabalha com e sobre a dor. Violentando-se frequentemente e explorando os limites da exposição pessoal, da pele e do corpo, confundindo umbilicalmente vida e arte, o trabalho de Liddell varre com pulsão testemunhal os males do mundo e, sobretudo, da condição da mulher. Cortes, sangue, intoxicações, álcool, excesso, sémen, genitais, sexo, dor auto-infligida, linguagem obscena, violações, assassínios, violência, tortura, escarificações, são motivos frequentes no seu trabalho, que sinalizam eximiamente a fragilidade do corpo humano perante as grandes máquinas institucionais: governos, empresas, igrejas, polícias, casamentos, familias, em suma, todas as formas organizadas de poder. Contudo, muito mais do que um puro turbilhão catártico ou acto de auto-flagelação penitente, o trabalho de Liddell revela um perspicaz e desabrido olhar político. Orgânico e visceral, é certo, mas nem por isso menos calculado, programado e certeiro.

Porque o sujeito em dor está normalmente privado dos recursos do discurso, não é surpreendente que a linguagem para a dor seja trazida por aqueles que não estão pessoalmente em dor mas que falam por aqueles que estão. (Scarry 1985: 6)

E a voz de Liddell, embora profundamente pessoal e individuada como poucas, consegue ser mais universal do que doméstica. Consegue fazer do seu corpo o campo de batalha política para um furioso jogo de denúncia, 
lamento e, por vezes, também propaganda (veja-se a maneira inflamada e panfletária como frequentemente se dirige ao público).

A casa da força parte da infernal situação de Ciudad Juarez, Chihuahua, México, considerada a cidade mais violenta do mundo. Com cerca de dois milhões e meio de habitantes, localizada perto da fronteira com os Estados Unidos, é geograficamente estratégica para os senhores da droga que se servem dela como palco para sangrentas guerras, tendo esta situação piorado desde que Felipe Calderón, o presidente mexicano, declarou guerra aos cartéis, em 2006. Desde então, a violência tem escalado para níveis incomportáveis. A somar a esta situação catastrófica, desde o início da década de noventa que Ciudad Juarez tem sido também uma testemunha impotente dos mais barbáricos actos de violência de género, ascendendo já a várias centenas o número de mulheres violadas e assassinadas. De acordo com dados da Amnistia Internacional, entre Janeiro e Outubro de 2010, foram mortas mais de 300 mulheres. Estes repetidos feminicídios, frequentemente por resolver, têm motivado, ao longo dos anos, muitos trabalhos de investigação jornalística, documentários, álbuns, concertos, livros de poesia, trabalhos plásticos e acções humanitárias várias - mas a violência continua, imparável.

0 espectáculo de Angélica Liddell começa pelo signo do trauma. Depois de uma insólita epígrafe, onde uma criança ameaça, lendo que "não há montanha, nem selva, nem deserto que nos livre do mal que os outros preparam para nós", abandonando o palco num bizarro avião de brincar, cor-de-rosa, duas mulheres semi-nuas, com as cuecas pelos tornozelos, aparecem deitadas no chão, prostradas entre flores e fruta. Relatam episódios de violência doméstica. De seguida, sentam-se a uma pequena mesa, carregando a mesma prostração, para beber cerveja fumar, trocar carícias, sorrisos e murmúrios. Entra depois mais uma mulher, Angélica Liddell, com pulsão de comício a anunciar que rebenta por dentro. Convida um grupo de Mariachis para tocar e cantar corridos mexicanos (género popular que serve muitas vezes de hino aos gangues de traficantes). Os temas das músicas anunciam insidiosamente as traves mestras do espectáculo. Liddell canta, gritando: "Borrachita de tequila llevo siempre el alma mía / Para ver si se mejora de esta cruel melancolía / Ay, por ese querer / Pues qué le voy a hacer / Si el destino me lo dio para siempre padecer". Os Mariachis cantam a aflitiva canção do "Preso número nove", um homem que se sentiu "obrigado" a matar a sua mulher adúltera e um amigo desleal. Assim, solidão e desamor misturam-se explosivamente com estereótipos de género e formas institucionalizadas de exercer o poder. No programa, Liddel explica muito claramente: "Do mesmo modo que as piadas de judeus culminam em Auschwitz, as rotinas de desprezo pela mulher culminam em feminicídio".

A exploração destes motivos vai habitar e informar as diferentes cenas do espectáculo que se prolonga por mais de cinco horas, naquilo que se configura como uma sedutora máquina de cansar, lenta e programadamente, o corpo. Como se na exaustão pudesse estar a superação do confronto com o horror. 0 espectáculo divide-se em três partes, todas distintas na sua articulação. A primeira é a mais festiva, dominada pela presença dos Mariachis e pelas três figuras femininas. Seduzindo o espectador, mapeia-se a zona de impacto do espectáculo, algures entre o belo e o trash, entre uma disfórica noite no café e uma intervenção politica. A segunda parte é Liddell sobre Liddell: a propósito dos seus próprios males de amor e de uma viagem a Veneza com o coração destroçado, a criadora cruza relatos de guerra com cibersexo, anti-semitismo com restaurantes kosher, Vivaldi com Woody Allen, halterofilismo e exercicios cardiovasculares com escarificação. Na terceira parte, com um Ford Fiesta no palco, ergue-se um cemitério de cruzes para que se relatem as terriveis atrocidades cometidas sobre as mulheres de Ciudad Juarez, fazendo convergir rigor jornalistico com poesia. Mas, em todas as partes, sempre a mesma gestão meticulosa e milimétrica dos efeitos produzidos. Mulheres que se esfregam com limões, que chupam limões, que fumam, que se queimam com cigarros, que cantam ao microfone, que se cortam com giletes, que transportam pesados sofás, que se exercitam como num ginásio, de peito nú: Pietas, ao mesmo tempo sôfregas e agónicas. Apesar da atmosfera de revolta iminente, descontrolada, as imagens criadas são de uma depuração estilística primorosa. Sucedem-se quadros síntese, poderosos na abstracção que sugerem: mulheres correm em círculos enquanto bebem cerveja ao som de uma parola música de matiné; Liddell muscula-se ao som de música clássica; uma enfermeira colhe sangue às três mulheres; um campeão de halterofilismo vira um carro; uma mulher simula tocar piano gesticulando no ar; uma mulher rebenta balões pendurados numa cruz a tiros de pressão de ar...

Atómico, feminino e visceral, o espectáculo é, em grande medida, carburado pela extraordinária banda sonora, que vai da festiva música dos Mariachis a Vivaldi, de Brahms ao magnífico violoncelo de Pau de Nut, que introduz no espectáculo uma suspensão notável, seja na criação das etéreas atmosferas, seja na interpretação das irresistiveis versões de Ne me quitte pas ou Love me tender.

"Tenho a convicção de que a ferramenta mais poderosa na performance contemporânea é o próprio artista", declara Marina Abramovic, introduzindo a didáctica obra de Colette Conroy, Theatre \& The Body. Nesta obra, a autora inicia a sua exposição citando o manual póstumo de Sarah Bernhardt (A arte do teatro, 1924), onde a diva francesa proclamava que só os corpos fisicamente perfeitos e bem proporcionados deviam aparecer em palco, veiculando a ideia de que o que se vê em palco deve resultar da execução virtuosa de uma intenção artística, sublinhando a noção de que actos involuntários em cena não têm significado isto apesar de escrever este manual quando prosseguia a sua carreira com uma perna amputada, de suscitar curiosidade sórdida enquanto figura bizarra, e de o seu estatuto esmagar dramaturgicamente as personagens que apresentava. 


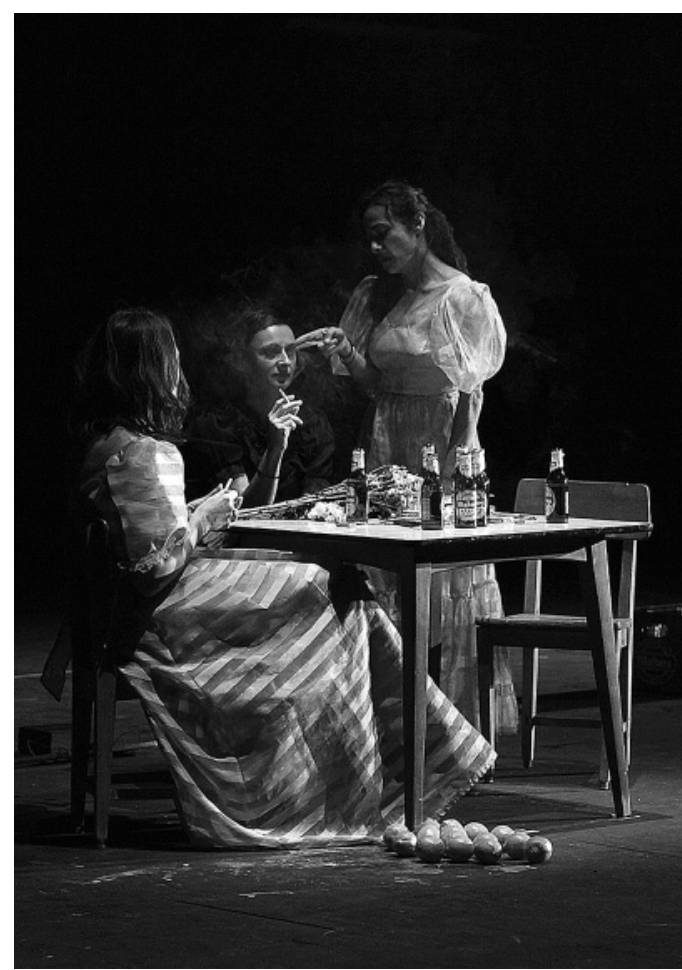

0 exemplo paradoxal de Sarah Bernhardt serve a Conroy para expor quatro ideias sobre teatro e sobre o corpo. Assim, e de acordo com a autora, há que considerar primeiro as convenções de apresentar e de ver os corpos no palco. Estas convenções - que terão que ver com a maneira como se entende a relação entre personagem e actor, entre corpo estático e em movimento, virtuosismo e competência artística - variam consoante o contexto e determinam a maneira como se entenderão o treino dos actores, a escrita dramática ou a encenação. Em segundo lugar, afirma Conroy, o corpo é um local de poder onde este pode ser questionado e explorado. "Quer o manual da Bernhardt, quer a sua experiência com a curiosidade sórdida dos então-paparazzi alertam-nos para o facto de que o público olha para os corpos por todo o tipo de razões. Grande arte e bizarria parecem pertencer a universos distintos, mas neste caso surgem juntos" (Conroy 2010: 5), clarifica a autora. Em terceiro lugar, o corpo pode ser utilizado como uma estratégia de análise ou como um ponto de vista. "A análise do corpo no palco também nos diz algo sobre o corpo que assiste. [...] A análise é sempre determinada pelas restrições ou possibilidades que o corpo impõe ou permite. 0 espectador 'ideal' existe somente como uma ideia abstracta" (Ibidem: 6). Por último, há que distinguir "corpo" de "corpos", sendo que "corpo" remete para uma ideia ou para um ideal, e "corpos" para objectos físicos que diferem radicalmente uns dos outros.

0 espectáculo de Liddell articula estas questões como poucos. Combina não-actores com intérpretes de virtuosismo inquestionável, suga o exótico de todos os corpos, defrauda a expectativa de tensão cénica dinâmica (com, por exemplo, cenas de 20 minutos onde três mulheres simplesmente mudam sofás de lugar), usa o corpo como locus para uma anatomia da violência e do poder $e_{\text {, }}$ hostilizando as figuras masculinas evocadas, relembra a cada cena o género/sexo do espectador.

Mas a força de Liddell advém também do modo furioso como lê o mundo. Os corpos que apresenta são corposvitima, tal como os entende Olivier Neveux. Destinamse a suscitar a piedade (ou o terror) em tempos de anestesia geral, quase como que exercendo uma chantagem moral. Mas, simultaneamente, são também corpos-oprimidos, frágeis, que na sua fragilidade sucumbem às pressões institucionais e se tornam suas vitimas.

0 corpo do oprimido é, certamente, um corpo destinado ao sofrimento, corpos assassinados, violados, discriminados. Mas não se resume a isto. Aquilo de que se trata nesta redução é ambiguo. Por um lado, está a apreensão estratégica que o oprimido tem do seu próprio corpo (da sua experiência subjectiva); por outro lado, a conformação com as normas hegemónicas. (Neveux 2007: 104)

0 corpo-oprimido é bastante mais "discreto", sendo a violência exercida sobre ele muitas vezes invisivel ou nem sequer nomeada. É a estes corpos, aos vitimizados e aos oprimidos, que Liddell empresta a voz.

\section{Referências biliográficas}

CONROY, Colette (2010), Theatre \&t the Body, Foreword by Marina Abramovic, Houndmills, Basingstoke, Hampshire, Palgrave Macmillan.

LIDDELL, Angélica (2007), "Lesões incompativeis com a vida", Triptico da aflição, trad. Alberto Augusto Miranda, Évora, Intensidez, pp.167-175.

NEVEUX, Olivier (2007), "L'état de victime: Quelques corps dans la scène théâtrale contemporaine", Actuel Marx: Corps dominés, corps en rupture, Paris, Presses Universitaires de France, premier semestre, Avril, pp. 99-108.

SCARRY, Elaine (1985), The Body in Pain. The Making and Unmaking of the World, New York and Oxford, Oxford University Press.
A casa da força,

de Angélica Liddell,

Atra Bilis, 2011,

fot. Julio Calvo. 